\section{Renewable energy sources and storage}

LEICESTER, NEWMAN AND WRIGHT claim to have invalidated Ryle's ${ }^{2}$ hypothesis that windpower could make a substantial and economical contribution to Britain's electricity supply, once shortterm $(150-\mathrm{h})$ thermal storage is provided at places of end-use. The counterargument of Leicester et al. ${ }^{1}$ seems to be based on two principal observations. (1) Plots of average heat demand against mean windpower output, which show that the standard deviation of windpower output is large and decreases only slowly with storage capacity. And (2), their "extreme example" for which the mean wind energy available over the period 1 February-31 March 1975 was about 54\% of the long-term average wind energy. Unfortunately, neither of these observations provides a test of Ryle's hypothesis.

Observation (1) confirms the wellknown fact that windpower is very variable. However, since the probability distribution of windpower is highly skewed in general, it is not particularly useful to quote standard deviations. More importantly, the scatter diagrams do not necessarily provide useful information on the crucial problem of storage content. The proposition by Leicester et al. that their interpretation of Ryle's thesis implies that the points in their Fig. $2 b$ should be grouped around the straight line through the origin of slope unity, is false. The grouping is sufficient but not necessary. Because windpower is proportional to the cube of windspeed, the store can be filled quickly but will be emptied slowly.

A simple example brings out this inadequacy of the scatter diagrams. If the daily output is constant at 1 unit, which seems to be a reasonable first approximation to the data presented, then 11 days' successive input of $\frac{1}{2}$ unit followed by a day with an input of 6 units keeps the store non-empty at all times, given that it was initially full. Yet the running 6-day average inputs are $\frac{1}{2}$ for half the time and $1 \frac{1}{2}$ for the rest, giving a wide scatter.

In contrast to their scatter diagram (Fig. 2) which is not helpful, quantitative information on windpower reliability is obtained from plots of power availability or capacity factor expressed as a function of storage capacity ${ }^{3-5}$.

Observation (2) merely reiterates the well-recognised point that windpower plus short-term storage alone cannot satisfy power demand with a probability of unity. However, Ryle ${ }^{2}$ does not assume that there are no conventional sources of power feeding the grid. We suggest that some of the real questions of quantitative significance raised by Ryle's work are as follows. First, what is the probability of low-wind periods of a given length? Second, how much conventional (that is, non-renewable) baseload, intermediate load and peakload capacity must be retained in a grid fed by windpower to ensure that low-wind periods can be covered with a probability close to unity? Third, what are the additional economic costs and benefits of such a hybrid grid? For example, the costs of extra start-ups of conventional power plants during low wind periods and the losses of unutilised windpower when storages are full; the benefit in replacing new or retired fossilfuel and nuclear plants with windpower or other renewable sources of energy; fuelsaving benefits when de-controlled as well as controlled prices are considered for fossil fuels. Finally, by how much are the answers to the second and third questions changed when a more flexible method of load switching and pricing is introduced? Such an automatic rationing system is technically feasible and could mean that instead of freezing over the period 7-16 February 1975, CEGB all-electric householders would have experienced simply a fall in home temperatures of (say) $5^{\circ} \mathrm{C}$ over the longer period $2-16$ February. For the case of central or substation storage, we have found that a user strategy in which part of the windpower output contributes to the immediate demand and part is proportional to the fraction of energy in storage, yields a substantial increase in the availability of windpower, compared with the strategy of simply following demand (M.D. and K. Malafant, in preparation).

Leicester et al. ${ }^{1}$ do not attempt to modify user demand, nor consider probabilities of extreme events, nor hybrid systems, nor economics of any kind. Their interpretation of their scatter diagrams is based on a false proposition. It is, therefore, difficult to understand the basis of their assertion that Ryle is "probably incorrect" on relative economics and that "sufficient work has already been done to demonstrate that 150 -h storage is quite inadequate to smooth the output of wind generators".

We thank Jeff Wood, Sue Carpenter and Brian Martin for helpful discussions.

\section{MARK DIESENDORF}

MARK WESTCOTT

\section{CSIRO Division of Mathematics}

\& Statistics,

PO Box 1965, Canberra City,

A.C.T. 2601, Australia

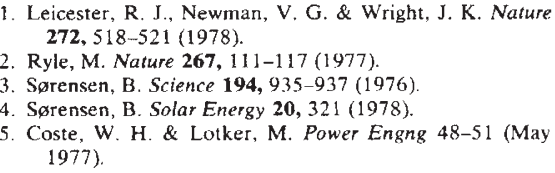

1. Leicester, R. J., Newman, V. G. \& Wright, J. K. Nature 272, 518-521(1978)

2. Ryle, M. Nature 267, 111-117 (1977)

3. Sørensen, B. Science 194, 935-937 (1976).

4. Sørensen, B. Solar Energy 20, 321 (1978).

5. Coste, W. H. \& Lotker, M. Power Engng 48-51 (May 1977).

LEICESTER ET AL. REPLY-Since our earlier work we have extended our analysis to determine the amount of storage that would have been needed to match heating demand to windpower output throughout the period 1 October 1974 to 31 March 1975, assuming an energy balance over the period as a whole. We have done this by calculating and then adding together the maximum cumulative surplus and deficit of windpower output relative to heating consumption over the 6 months. The storage requirement turns out to be $1,124 \mathrm{~h}$, thus substantiating our contention that $150-\mathrm{h}$ storage is quite insufficient.

We have also calculated the normalised averages of heating demand and windpower output for 1,124 -h periods within the 6 months and find that the former extend from 0.9 to 1.04 and the latter from 0.4 to 1.73 . The standard deviation of the heating demand is now 0.028 and that of the wind energy is 0.394 , which are about half the values with 150 -h storage. Although these results support Diesendorf and Westcott's argument that zero scatter is not a necessary condition of sufficiency of storage, they do show that with sufficient storage the scatter is very much smaller than for 150 -h storage as shown in our Fig. $2 b$.

Diesendorf and Westcott raise a number of other questions which, we agree, are relevant in a wider context. However, there is clearly a difference in view between us on what Ryle has proposed. Our understanding of his concept is that, he contends that, by controlling the electrical input to storage for space heating and hot water supply by remote switching in accordance with the availability of windpower output, the heating demand can be fully and reliably satisfied without recourse to supplies from other generating plant. We believe that our analysis shows conclusively that $150-\mathrm{h}$ storage is not sufficient to support Ryle's contention, but this does not mean that the use of storage with renewable energy sources is unimportant. Indeed, while it was not the purpose of our article to do more than examine the storage proposition as formulated by Ryle, we are nevertheless continuing to study the question of integrating large amounts of windpower into the CEGB's system and this will include consideration of questions (1), (2) and (3) posed by Diesendorf and Westcott.

With regard to their fourth question, a policy of selective rationing of electricity for heating is not feasible since consumers could not be denied freedom to resort to electrical supplementary heating at times of storage deficiency in cold spells. Such use would inevitably occur and the consequent peak load on the supply system could be close to what it would have been without windpower generation with the result that the latter would have minimal firm capacity.

R. J. LEICESTER

V. G. NEWMAN

J. K. WRIGHT

Planning Department,

CEGB Land House,

Newgate St,

London EC1, UK 